\title{
Daily Physical Activity Patterns and Their Association With Health-Related Physical Fitness Among Aging Workers-The Finnish Retirement and Aging Study
}

Citation for published version (APA):

Stenholm, S., Pulakka, A., Leskinen, T., Pentti, J., Heinonen, O. J., Koster, A., \& Vahtera, J. (2021). Daily Physical Activity Patterns and Their Association With Health-Related Physical Fitness Among Aging Workers-The Finnish Retirement and Aging Study. Journals of Gerontology Series A-Biological Sciences and Medical Sciences, 76(7), 1242-1250. https://doi.org/10.1093/gerona/glaa193

Document status and date:

Published: 01/07/2021

DOI:

10.1093/gerona/glaa193

Document Version:

Publisher's PDF, also known as Version of record

\section{Document license:}

Taverne

Please check the document version of this publication:

- A submitted manuscript is the version of the article upon submission and before peer-review. There can be important differences between the submitted version and the official published version of record.

People interested in the research are advised to contact the author for the final version of the publication, or visit the DOI to the publisher's website.

- The final author version and the galley proof are versions of the publication after peer review.

- The final published version features the final layout of the paper including the volume, issue and page numbers.

Link to publication

\footnotetext{
General rights rights.

- You may freely distribute the URL identifying the publication in the public portal. please follow below link for the End User Agreement:

www.umlib.nl/taverne-license

Take down policy

If you believe that this document breaches copyright please contact us at:

repository@maastrichtuniversity.nl

providing details and we will investigate your claim.
}

Copyright and moral rights for the publications made accessible in the public portal are retained by the authors and/or other copyright owners and it is a condition of accessing publications that users recognise and abide by the legal requirements associated with these

- Users may download and print one copy of any publication from the public portal for the purpose of private study or research.

- You may not further distribute the material or use it for any profit-making activity or commercial gain

If the publication is distributed under the terms of Article $25 \mathrm{fa}$ of the Dutch Copyright Act, indicated by the "Taverne" license above, 


\title{
Daily Physical Activity Patterns and Their Association With Health-Related Physical Fitness Among Aging Workers- The Finnish Retirement and Aging Study
}

\section{Sari Stenholm, PhD, ${ }^{1,2, *, \bullet}$ Anna Pulakka, PhD, ${ }^{3}$ Tuija Leskinen, PhD, ${ }^{1,2}$ Jaana Pentti, BSc, ${ }^{1,4}$ Olli J. Heinonen, MD, PhD, ${ }^{5}$ Annemarie Koster, PhD, ${ }^{6}$ and Jussi Vahtera, MD, PhD ${ }^{1,2,0}$}

'Department of Public Health, University of Turku and Turku University Hospital, Finland. ${ }^{2}$ Centre for Population Health Research, University of Turku and Turku University Hospital, Finland. ${ }^{3}$ Public Health Promotion Unit, Finnish Institute for Health and Welfare, Helsinki, Finland. ${ }^{4}$ Clinicum, Faculty of Medicine, University of Helsinki, Finland. ${ }^{5}$ Paavo Nurmi Centre \& Unit for Health and Physical Activity, University of Turku, Finland. ${ }^{6}$ Department of Social Medicine, CAPHRI Care and Public Health Research Institute, Maastricht University, The Netherlands.

*Address correspondence to: Sari Stenholm, PhD, Department of Public Health, University of Turku, Joukahaisenkatu 3-5, 20014 Turku, Finland. E-mail: sari.stenholm@utu.fi

Received: March 16, 2020; Editorial Decision Date: July 29, 2020

Decision Editor: Anne B. Newman , MD, MPH, FGSA

\begin{abstract}
Background: This study aimed to identify accelerometer-measured daily physical activity patterns, and to examine how they associate with health-related physical fitness among aging workers.

Methods: The study population consisted of 263 participants (mean age 62.4 years, SD 1.0) from the Finnish Retirement and Aging study, who used wrist-worn ActiGraph accelerometer for at least 1 week including both workdays and days off. Health-related physical fitness measures included body composition (waist circumference, bioimpedance), cardiorespiratory fitness (bicycle ergometer test), and muscular fitness (push-up and chair rise tests).

Results: Based on the latent class trajectory analysis, 6 trajectories were identified for workdays showing variation in activity level on working hours and on evening hours. Moderate activity during working hours and increase of activity level in the evening was associated with the most favorable health-related fitness in comparison to low activity throughout the workday: waist circumference $90.0 \mathrm{~cm}(95 \%$ confidence interval [CI] 85.5-94.5) versus $99.5 \mathrm{~cm}$ (95\% CI 96.8-102.3), fat mass $13.9 \mathrm{~kg}$ (9.3-18.5) versus $23.8 \mathrm{~kg}$ (20.2-27.4), cardiorespiratory fitness $33.4 \mathrm{~mL} / \mathrm{kg} / \mathrm{min}$ (95\% CI 31.4-35.3) versus $29.1 \mathrm{~mL} / \mathrm{kg} / \mathrm{min}$ (95\% CI 27.8-30.3) (adjusted for age, sex, days off activity, smoking, and alcohol). For the days off, 2 different trajectories were identified, but they differed only in terms of level and not by timing of physical activity. Conclusions: A large variation in the workday physical activity patterns was observed among aging workers. Independent of worktime activity, people who were more active in the evenings had more favorable health-related physical fitness than those who were less active throughout the day.
\end{abstract}

Keywords: Body composition, Latent class analysis, Leisure-time physical activity, Occupational physical activity, Physical fitness

Physical activity is widely reported to improve health and reduce risk of chronic condition (1). It has also been shown that physical inactivity reduces productivity at work (2) as well as increases risk for sickness absence (2), disability pension and unemployment (3). With the aging workforce and national goals to extend working lives into older ages in western countries, there is a need for detailed under- standing of the physical activity behavior among aging workers and their associations with health indicators.

Several studies have recently described daily patterns of physical activity based on accelerometer measurements in various subpopulations, including aging workers (4), and found that the level and patterns of physical activity differ by sex, age groups, 
and working status (4-6). Examining patterns of total physical activity may be especially informative among older adults who engage less in moderate-to-vigorous intensity activities. However, the current research is still mainly focused on presenting average activity values and patterns of the target population or its subgroups, although wide between-individual variation exists, for example, due to differences in work-related activities or leisure-time activity preferences (4). Consequently, there is a need for more detailed understanding of the heterogeneity in people's activity behavior, because the health-related effects of physical activity may differ depending on the context and setting of physical activity. A suitable statistical approach to recognize different physical activity patterns is a group-based trajectory modeling, such as latent class trajectory analysis (7), which allows identification of potential latent subgroups within the study population that show similar patterns of activity throughout the day.

To our knowledge, only 2 previous studies have utilized accelerometer data to describe latent activity patterns in working-age adults $(8,9)$. Metzger et al examined physical activity patterns across 7 -day week in a population-based cohort study from the United States (9), and Gupta et al reported movement behavior profiles across work and leisure time during workdays based on a Danish study, mostly consisting blue-collar workers (8). The main limitation in these studies is that they did not specifically consider differences between workdays and days off, although activity patterns on workdays and days off are inherently different due to work-related tasks. Moreover, since days off may provide opportunities for leisure-time physical activity, activity level on days off should be therefore considered when examining health associations with workday physical activity. Importantly, both of these earlier studies were based on adult working-age population, and therefore further research among aging workers is warranted.

Distinguishing different activity patterns within a day and between days is important, because very little is known about which activity patterns are the most beneficial for health. It has been suggested, for example, that health-related effects of physical activity at leisure time and at work are different: moderate and high levels of leisure-time physical activity are associated with reduced risk of cardiovascular diseases $(10,11)$, long-term sickness absence (12), and mortality (13), whereas high occupational physical activity shows no association or increased risk of these health outcomes (10-12). However, these findings are based on self-reported physical activity at work and leisure, and thus there is a need to examine daily physical activity patterns based on more objective measurement of physical activity. Moreover, the associations of daily physical activity patterns with more proximal activity-related health indicators, such as health-related physical fitness, are poorly understood, although health-related physical fitness is important not only for daily functioning, but also in the prevention of major chronic diseases, including cardiovascular disease, type 2 diabetes, bone and joint diseases, cancer, and depression (14).

To address some of the gaps in the literature, the first aim of this study was to identify accelerometer-measured daily physical activity patterns during workdays and days off among aging workers by using the latent class trajectory analysis. The second aim was to examine how these physical activity patterns were associated with health-related physical fitness, including body composition, cardiorespiratory fitness, and muscular fitness, by taking into account the physical activity level on days off.

\section{Materials and Methods}

\section{Participants}

The study population consisted of participants from the Finnish Retirement and Aging (FIREA) study, an ongoing longitudinal cohort study of older adults in Finland established in 2013. Details of the design and implementation of the FIREA study have been reported in detail elsewhere (15). Shortly, participants were first contacted 18 months prior to their estimated retirement date by sending a questionnaire. After responding to the questionnaire, Finnishspeaking participants with estimated retirement date between 2017 and 2019, who lived in the Southwest Finland and were still working, were invited to participate in a clinical substudy $(n=773)$. Of them, 290 participated in the clinical substudy and 281 participants provided accelerometer data on at least 4 valid days with $\geq 10$ hours of waking wear time. Because the focus was on daytime physical activity patterns (hours between 6:00 to 22:00), we excluded participants who worked night or evening shifts (working hours after 18:00) during the measurement week, or who had less than 8 hours of measurement between 6:00 and 22:00, resulting in an analytic sample of 263 participants.

Informed consent was obtained from all the participants. The FIREA study was conducted in line with the Declaration of Helsinki and was approved by the Ethics Committee of Hospital District of Southwest Finland.

\section{Accelerometer Measurements}

Physical activity was measured 24 hours per day with a triaxial ActiGraph (wActiSleep-BT) accelerometer (ActiGraph, Pensacola, FL) worn on nondominant wrist for minimum of 7 days and nights, including at least 2 workdays and 2 days off.

The ActiGraph was initialized to record at $80 \mathrm{~Hz}$. During a study visit, a study nurse gave the participants both oral and written information on how to wear the accelerometer. The participants were instructed to wear the device at all times, including during water-based activities such as swimming, but to remove it for sauna bathing. In an accompanying log, the participants were asked to mark whether the measurement day was a workday or day off, and record the time of the beginning and end of each work shift for each workday they wore the device. After the measurement period, the participants returned the device and the log by mail. Data collection took place between October 2015 and May 2018 including all the 4 seasons ( $28 \%$ spring, $9 \%$ summer, $27 \%$ fall, and $37 \%$ winter).

Data from the accelerometers were downloaded and converted into 60-second epochs in the ActiLife software, version 6.13 (ActiGraph). We used the vector magnitude (VM) counts per minute (CPM) which was calculated as the square root of the sum of squared activity counts of the 3 axes. We included wake wear time between the first and last time recorded in the participant log. We excluded nonwear time using the algorithm developed by Choi et al, which has been validated for wrist-worn triaxial accelerometers (16). We further excluded sleep time by the ActiGraph algorithm available in the ActiLife software $(17,18)$ and hours with less than 60 minutes of wear time. A valid measurement day was defined as minimum of 10 hours of wake wear time (19). In the current study, the mean number of valid measurement days was 8.7 (SD 1.8), which clearly exceeds the commonly used criteria of 4 valid days (19). For the analyses we used 2 measures of physical activity: (i) mean VM CPM for each hour of the day (hours between 6:00 and 22:00) for the trajectory analyses and (ii) mean daily VM CPM as an indicator of total physical activity volume. 


\section{Assessment of Health-Related Physical Fitness}

Three components of health-related physical fitness were measured: body composition, muscular fitness, and cardiorespiratory fitness.

During a clinical visit, waist circumference was measured to the nearest $0.1 \mathrm{~cm}$ directly on the participant's skin, in the midpoint of the lowest rib and the iliac crest, during light exhalation. The measurement was repeated twice, and the mean value was used in the analysis. Body composition was measured with 8-polar multifrequency bioelectrical impedance analysis (BIA) (Inbody 720, Biospace Co., Seoul, Korea). (Inbody 720, Biospace Co., Seoul, Korea) with the participants wearing only light clothing and having had a 10-hour fast, and avoiding strenuous exercise the day before the measurements. For the current study we used total fat mass $(\mathrm{kg})$ and skeletal muscle mass $(\mathrm{kg})$ as the body composition indicators. Due to a device malfunction, 7 participants did not receive valid results for body composition.

After the body composition measurement, lower extremity performance was measured with a chair rise test (20), in which participants were asked to stand up and sit down as quickly as possible 10 times with their hands folded across their chest. Time (in seconds) to complete the test was recorded. One person was unable to perform the test due to back pain.

Physical fitness tests were performed by an experienced exercise physiologist in a standard sequence within 1 month from the accelerometer measurement and the first clinical visit. Measurement of upper-body strength and stability was tested with a modified push-up test (21). Participants were asked to perform as many pushups as possible during 40 seconds. Number of repetitions was used in the analyses. If participant was unable to successfully perform at least 1 push-up, then value 0 was given. Eighteen participants did not conduct the test due to musculoskeletal pain in the shoulder or back region, 18 had contraindications (arrhythmia, coronary artery disease, myocardial infarction, or other cardiovascular disease), and 28 were unwilling to participate to the second study visit.

After individually performed muscular fitness tests, cardiorespiratory fitness was measured in a group of 3-4 persons with indirect submaximal bicycle ergometer test with Ergoselect $100 \mathrm{~K}$ (Ergoline, Bitz, Germany) according to the American College of Sports Medicine guidelines (22). The test started with a 5-minute warm-up period with a workload 20-40 watts for women and $30-50$ watts for men. The 12-minute test consisted 3 graded workloads and the load was increased every 4 minutes according to the protocol until $85 \%-90 \%$ of the age-predicted maximal heart rate (210-0.65* age) or the rating of perceived exertion over 15 was achieved. Maximal working capacity was extrapolated by using workloads and heart rates collected during the test and it was then converted into peak oxygen consumption (VO2peak) $(\mathrm{mL} / \mathrm{kg} / \mathrm{min}$ ) by using formula $(11.02 *$ watts $) /$ body weight +7 (22). Eighteen participants were unable to conduct the test because of contraindications (arrhythmia, coronary artery disease, myocardial infarction, or other cardiovascular disease) and 29 did not want to participate to the bicycle ergometer test.

\section{Assessment of Covariates}

Sex, date of birth, and occupational title were obtained from the register of pension institute Keva. The occupational titles were coded according to the International Standard Classification of Occupations (ISCO) and categorized into 3 groups: high (ISCO classes 1-2, managers and professionals), intermediate (ISCO classes $3-4$, associate professionals and office workers), and low (ISCO classes 5-9, service and manual workers). The ISCO was also used together with validated sex-specific job exposure matrix for physical exposures to identify physically heavy work (no vs yes) $(23,24)$.

Information from the questionnaire was used to define marital status (married or cohabiting vs not), current smoking (no vs yes), and alcohol use (no/moderate vs risk use [ $>24$ units for men and $>16$ units for women]). Chronic diseases diagnosed by a physician (angina pectoris, myocardial infarction, cerebrovascular disease, osteoarthritis, rheumatoid arthritis, diabetes, and asthma) were enquired in the questionnaire and participants were categorized as having no disease, 1 disease, or 2 or more diseases. Body mass index was calculated from self-reported weight and height and categorized into normal weight $\left(<25 \mathrm{~kg} / \mathrm{m}^{2}\right)$, overweight $\left(25-30 \mathrm{~kg} / \mathrm{m}^{2}\right)$, and obese $\left(\geq 30 \mathrm{~kg} / \mathrm{m}^{2}\right)$. To measure nonoccupational physical activity, respondents were asked to estimate their average weekly hours of leisuretime physical activity (including commuting) within the previous year in walking, brisk walking, jogging, and running, or their equivalent activities (25). The time spent on activity at each intensity level in hours per week was multiplied by the average energy expenditure of each activity, expressed in metabolic equivalent (MET) (26). Selfreported nonoccupational physical activity was categorized as low $<14$ MET, moderate $\geq 14$ to <30 MET, and high $\geq 30$ MET (27).

\section{Statistical Analysis}

Analyses were conducted in 2 stages. First, we examined the heterogeneity in the daily physical activity separately for workdays and days off by using latent trajectory analysis (PROC TRAJ in SAS 9.4, SAS Institute Inc., Cary, NC). We used Nagin's 2-step procedure to determine the optimal number trajectories and chose the number and order of regression parameters (28). In the first step, we fitted increasing number of trajectory models with curvilinear polynomial shape for physical activity until no improvement in model fit was observed. Assessment of model fit was based on Bayesian information criterion (BIC) values, Akaike information criterion (AIC) values, Log-likelihood, and posterior probabilities. In the second step, we tested models with quadratic and linear trajectories for the selected models chosen in the first step. The best-fitting trajectory model for workdays and days off was chosen, and used as a group variable in the following analytical stage.

Characteristics of the study population and by the trajectory groups are presented as mean values and standard deviations for the continuous variables and percentages for the categorical variables. To describe the daily physical activity volume across the trajectories, we calculated mean daily waking hour activity CPM and their $95 \%$ confidence intervals (CIs) by using analyses of covariance (ANCOVA, PROC GLM in SAS) and taking into account age and sex. Finally, we examined differences in health-related physical fitness between the trajectories of daily physical activity on workdays and days off by using ANCOVA. We started with age- and sex-adjusted model (model 1), then adjusted for physical activity pattern during days off/ workdays, smoking, and alcohol risk use (model 2). These covariates were chosen, because they can confound the association between daily physical activity and health-related physical fitness.

Finally, to examine selection into the current clinical substudy, we examined whether self-reported nonoccupational physical activity and body mass index, as well as sociodemographic characteristics and other health indicators differed between the participants of the current study and those FIREA participants who responded only to the survey and were either still working or retired at the time of the baseline survey. 
All analyses were performed using statistical software SAS version 9.4 (SAS Institute Inc.).

\section{Results}

Characteristics of the study population are shown in Table 1 . The participants were on average 62.4 (SD 1.0) years of age, majority of them were women and married or cohabiting. Occupational status was relatively equally distributed into high, intermediate, and low groups.

For the workdays, 6-trajectory solution of daily physical activity with curvilinear polynomial shape yielded the best fit $(\mathrm{BIC}=-34899.8 / \mathrm{AIC}=-34835.5)$. Model fit statistics of the latent trajectory analyses are presented in Supplementary Table 1. Figure 1 shows the 6 latent class trajectories for daily physical activity on workdays. Two trajectories included two thirds of the participants indicating groups of people who had constantly low physical activity during the day, named as "Low throughout the day" $(33 \%)$, and people who had moderate level physical activity during the day, but decreased in the evening, named as "Moderate during the day and decrease in the evening" $(32 \%)$. Other trajectories were "Low during the day and increase in the evening" $(7 \%)$, "Moderate during the day and increase in the evening" (12\%), "High during the day and decrease in the evening" $(10 \%)$, and "Highest during the day and active in the evening" $(6 \%)$. Figure 2 shows average daily physical activity volume across the workday trajectory groups. The highest activity volume was observed in the "Highest during the day and active in the evening" trajectory (3928 VM CPM, 95\% CI 3784-4073) and lowest in the "Low throughout the day" trajectory (1841 VM CPM, 95\% CI 1779-1902).
For the days off, 2-trajectory solution of daily physical activity with curvilinear polynomial shape yielded the best fit $(\mathrm{BIC}=-34999.1 /$ AIC $=$-34977.6) (Supplementary Table 1). As shown in Figure 1, both trajectories showed similar pattern throughout the day with increase in activity during midday following a decrease toward evening hours, and the trajectories differed only by the level: $60 \%$ of the individuals belonged to the lower activity trajectory and $40 \%$ to the higher activity trajectory. There was a clear difference in the mean daily physical activity volume between the lower activity (2042 VM CPM, 95\% CI 1972-2114) and the higher activity (2915 VM CPM, 95\% CI 2819-3011) trajectories (Figure 2).

Description of the study sample characteristics according to workday physical activity trajectory groups is shown in Table 1. "Low throughout the day" trajectory group was characterized by fewer women and lower days off activity compared to the other trajectory groups. On the other hand, physically heavy work, job strain, and not married or cohabiting were more common in the "High during the day and decrease in the evening" trajectory group than in the other trajectory groups. In addition, low occupational status was most common in the "High during the day and decrease in the evening" and the "Highest during the day and active in the evening" trajectory groups. Since work shifts start usually earlier in the morning in the service and manual occupations, this may partly explain higher morning activity in these 2 trajectories compared to the other trajectory groups. The trajectory groups did not markedly differ by smoking, alcohol risk use, or disease status. Lower days off activity was more common in those trajectory groups, which showed lower activity in the evenings.

Table 2 shows the mean levels of health-related physical fitness indicators according to the physical activity trajectory groups

Table 1. Descriptive Characteristics of the Participants by the Workday Physical Activity Trajectory Groups

\begin{tabular}{|c|c|c|c|c|c|c|c|c|}
\hline & $\begin{array}{l}\text { Total } \\
(n=263)\end{array}$ & $\begin{array}{l}\text { Low } \\
\text { Through- } \\
\text { out the } \\
\text { Day } \\
(n=87)\end{array}$ & $\begin{array}{l}\text { Low During } \\
\text { the Day and } \\
\text { Increase in } \\
\text { the Evening } \\
(n=18)\end{array}$ & $\begin{array}{l}\text { Moderate During } \\
\text { the Day and } \\
\text { Decrease in the } \\
\text { Evening }(n=85)\end{array}$ & $\begin{array}{l}\text { Moderate During } \\
\text { the Day and } \\
\text { Increase in the } \\
\text { Evening }(n=31)\end{array}$ & $\begin{array}{l}\text { High During } \\
\text { the Day and } \\
\text { Decrease in } \\
\text { the Evening } \\
(n=25)\end{array}$ & $\begin{array}{l}\text { Highest During } \\
\text { the Day and } \\
\text { Active in } \\
\text { the Evening } \\
(n=17)\end{array}$ & $\begin{array}{l}P \text { Value } \\
\text { for } \\
\text { Hetero- } \\
\text { geneity }\end{array}$ \\
\hline Age, mean $(S D)$ & $\begin{array}{l}62.4 \\
(1.0)\end{array}$ & $62.4(1.0)$ & $62.8(0.8)$ & $62.3(1.0)$ & $62.3(1.0)$ & $62.5(1.1)$ & $62.4(0.9)$ & .29 \\
\hline Women, \% & 82 & 63 & 94 & 87 & 87 & 100 & 100 & $<.0001$ \\
\hline $\begin{array}{l}\text { Married or } \\
\text { cohabiting, \% }\end{array}$ & 73 & 82 & 88 & 67 & 81 & 46 & 71 & .0044 \\
\hline $\begin{array}{l}\text { Occupational } \\
\text { status, } \%\end{array}$ & & & & & & & & $<.0001$ \\
\hline High & 38 & 52 & 56 & 38 & 32 & 0 & 18 & \\
\hline Intermediate & 34 & 36 & 39 & 44 & 29 & 20 & 6 & \\
\hline Low & 28 & 13 & 6 & 19 & 39 & 80 & 76 & \\
\hline $\begin{array}{l}\text { Physically } \\
\text { heavy work, \% }\end{array}$ & 15 & 5 & 0 & 4 & 23 & 72 & 41 & $<.0001$ \\
\hline Job strain, \% & 14 & 14 & 11 & 8 & 10 & 32 & 25 & .049 \\
\hline $\begin{array}{l}\text { Lower activity } \\
\text { on days off, \% }\end{array}$ & 40 & 89 & 39 & 60 & 23 & 56 & 18 & $<.0001$ \\
\hline Smoking, \% & 5 & 7 & 0 & 5 & 3 & 4 & 6 & .86 \\
\hline $\begin{array}{l}\text { Alcohol risk } \\
\text { use, } \%\end{array}$ & 10 & 9 & 6 & 15 & 3 & 4 & 6 & .29 \\
\hline $\begin{array}{l}\text { Number } \\
\text { of chronic } \\
\text { diseases, \% }\end{array}$ & & & & & & & & .31 \\
\hline 0 & 35 & 38 & 56 & 32 & 27 & 20 & 50 & \\
\hline 1 & 50 & 46 & 33 & 52 & 50 & 64 & 50 & \\
\hline$\geq 2$ & 15 & 15 & 11 & 15 & 23 & 16 & 0 & \\
\hline
\end{tabular}


on workdays. Participants in the "Low throughout the day" group, which indicates the least active group, had higher fat mass and waist
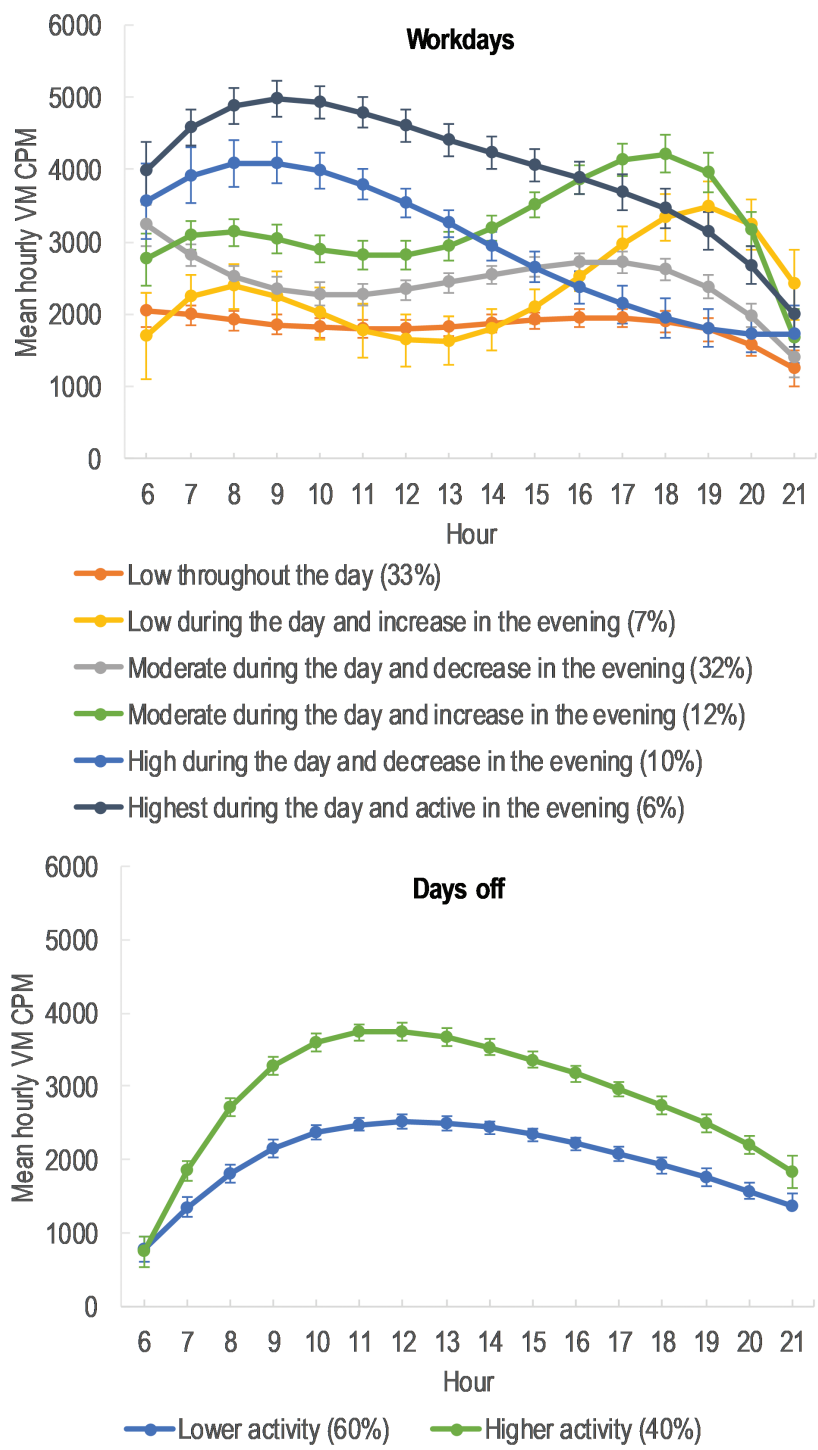

Figure 1. Trajectories of daily physical activity on workdays and days off. VM $\mathrm{CPM}=$ vector magnitude counts per minute. Full color version is available within the online issue. circumference compared to all other physical activity trajectory groups, except "High during the day and decrease in the evening" group and "Highest during the day and active in the evening" (only for fat mass), after accounting for physical activity pattern on days off and lifestyle factors. In addition, participants who were more active in the evenings than during working hours, that is, "Low during the day and increase in the evening" and "Moderate during the day and increase in the evening" trajectory groups, had the lowest waist circumference and fat mass. Skeletal muscle mass was relatively similar across the trajectory groups.

In terms of cardiorespiratory fitness, the participants in the "Low throughout the day" group performed poorer than the participants in the "Low during the day and increase in the evening," the "Moderate during the day and decrease in the evening," and the "Moderate during the day and increase in the evening" groups. Results for chair rise and push-up tests were poorest in the "Low throughout the day" and best in the "Moderate during the day and increase in the evening" groups. After accounting for physical activity pattern on days off and lifestyle factors, the statistical significant differences in cardiorespiratory fitness and push-up test remained only between the "Moderate during the day and increase in the evening" and the "Low throughout the day" groups.

Comparisons of health-related physical fitness indicators between the 2 trajectory groups on days off are shown in Table 3. Participants in the higher activity trajectory group had less adiposity, more muscle mass, and better physical fitness than those in the lower activity trajectory group when age and sex were adjusted for. After taking into account physical activity pattern on workdays and lifestyle factors, the differences across the groups attenuated, but remained statistically significant for muscle mass and cardiorespiratory fitness.

Finally, selection into the study was examined by comparing the study participants to those FIREA participants who responded only to the survey and were either still working or retired at the time of the baseline survey (Supplementary Table 2). The participants of the current study were physically more active and had lower body mass index compared to the working or retired survey participants. In addition, the participants included in the current analyses had higher occupational position, smoked less, and had fewer chronic diseases than the survey-only participants.

\section{Discussion}

Based on a well-characterized cohort of aging workers from Finland, we aimed at identifying daily physical activity patterns
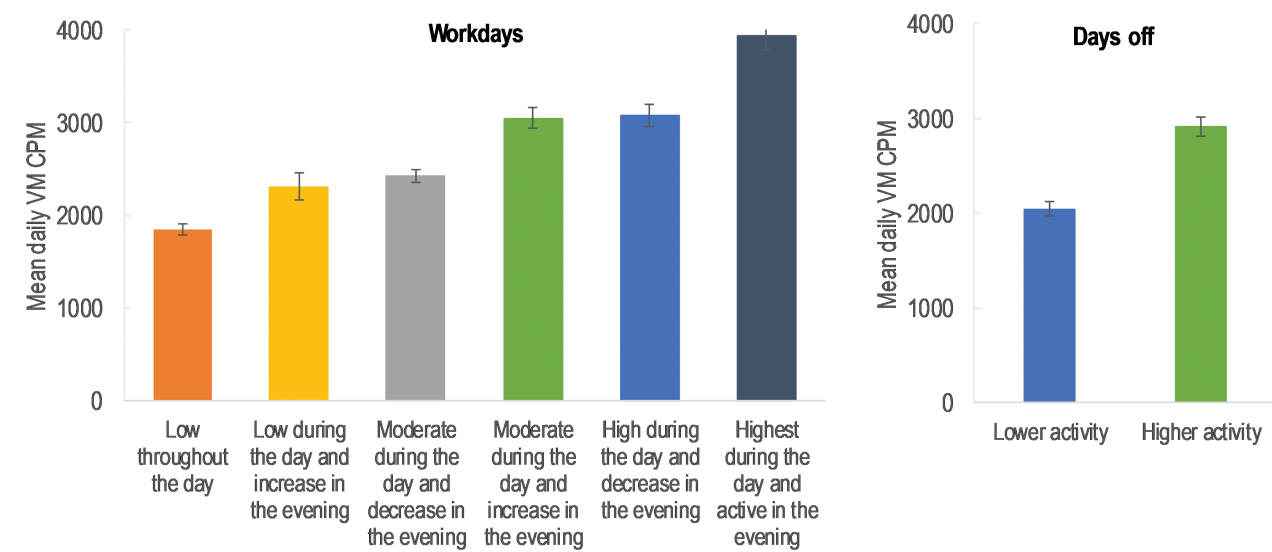

Figure 2. Mean daily physical activity volume (counts per minute) and their $95 \%$ confidence intervals (Cls) across the trajectory groups on workdays and days off. Adjusted for age and sex. VM CPM = vector magnitude counts per minute. Full color version is available within the online issue. 


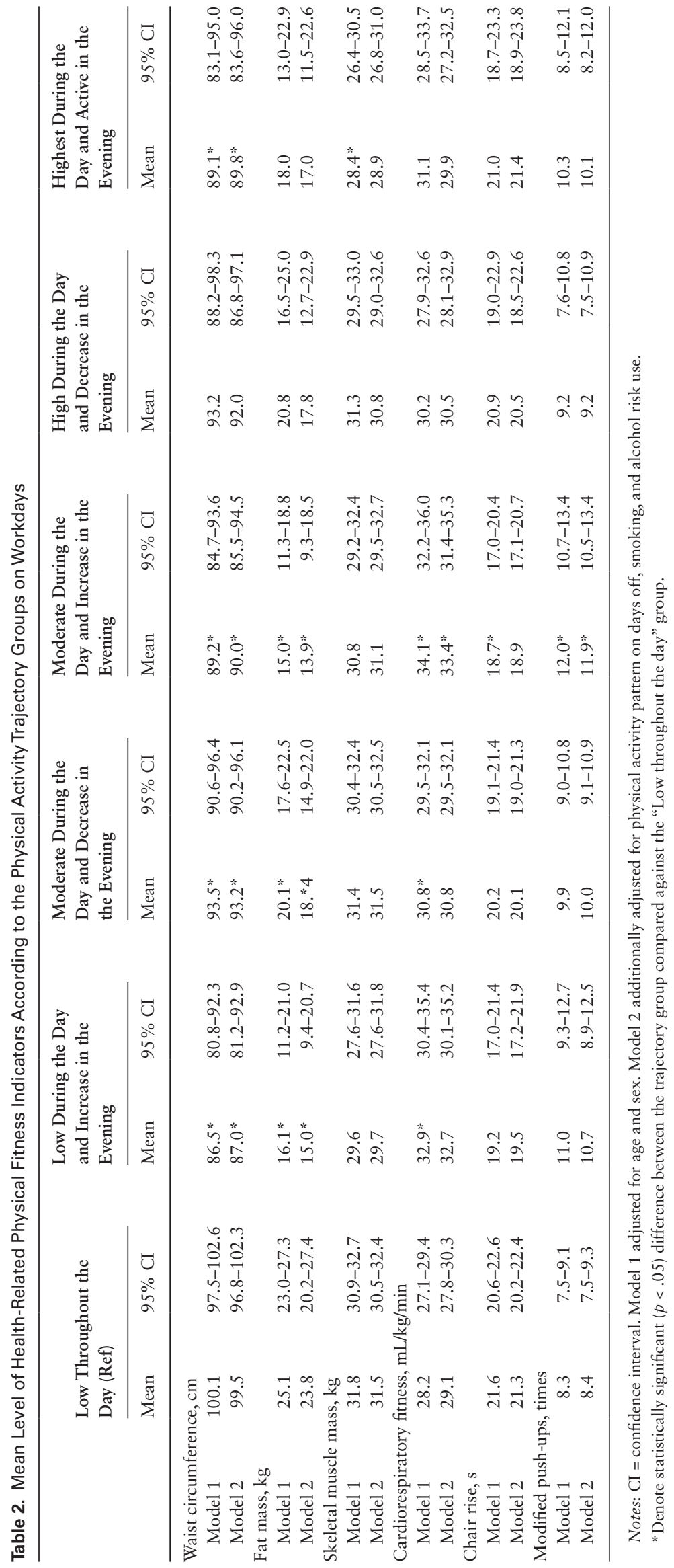


Table 3. Mean Level of Health-Related Physical Fitness Indicators According to the Physical Activity Trajectory Groups on Days Off

\begin{tabular}{|c|c|c|c|c|}
\hline & \multicolumn{2}{|c|}{ Lower Activity (Ref) } & \multicolumn{2}{|c|}{ Higher Activity } \\
\hline & Mean & $95 \% \mathrm{CI}$ & Mean & $95 \% \mathrm{CI}$ \\
\hline \multicolumn{5}{|c|}{ Waist circumference, $\mathrm{cm}$} \\
\hline Model 1 & 97.4 & $95.3-99.5$ & $91.2^{*}$ & $88.3-94.1$ \\
\hline Model 2 & 96.9 & $94.7-99.1$ & 91.5 & $88.5-94.4$ \\
\hline \multicolumn{5}{|c|}{ Fat mass, $\mathrm{kg}$} \\
\hline Model 1 & 22.8 & $21.0-24.6$ & $18.9 *$ & $16.5-21.3$ \\
\hline Model 2 & 18.0 & $14.6-21.4$ & 17.3 & $13.6-21.1$ \\
\hline \multicolumn{5}{|c|}{ Skeletal muscle mass, kg } \\
\hline Model 1 & 31.8 & $31.1-32.5$ & $30.2 *$ & $29.3-31.2$ \\
\hline Model 2 & 29.8 & $28.4-31.2$ & $28.5^{*}$ & $27.0-30.1$ \\
\hline \multicolumn{5}{|c|}{ Cardiorespiratory fitness, $\mathrm{mL} / \mathrm{kg} / \mathrm{min}$} \\
\hline Model 1 & 29.0 & $28.1-29.9$ & $32.5^{*}$ & $31.2-33.7$ \\
\hline Model 2 & 31.4 & $29.6-33.3$ & $34.1 *$ & $32.1-36.1$ \\
\hline \multicolumn{5}{|l|}{ Chair rise, $\mathrm{s}$} \\
\hline Model 1 & 21.1 & $20.3-21.9$ & $19.8 *$ & $18.7-20.9$ \\
\hline Model 2 & 21.2 & $19.6-22.8$ & 20.6 & $18.8-22.4$ \\
\hline \multicolumn{5}{|c|}{ Modified push-ups, times } \\
\hline Model 1 & 9.1 & $8.4-9.7$ & $10.4^{*}$ & $9.5-11.2$ \\
\hline Model 2 & 10.1 & $8.8-11.5$ & 10.6 & $9.1-12.1$ \\
\hline
\end{tabular}

Notes: $\mathrm{CI}=$ confidence interval. Model 1 adjusted for age and sex. Model 2 additionally adjusted for physical activity pattern on workdays, smoking, and alcohol risk use.

"Denote statistically significant $(p<.05)$ difference between the trajectory groups.

during workdays and days off as well as differences in health-related physical fitness between the patterns. We found 6 different trajectories on workdays, which were characterized by large variation in the daily physical activity in terms of amount and timing of physical activity. On the other hand, only 2 different patterns were observed on days off, and they differed only in terms of the level of physical activity, but not by the timing of physical activity. The present study enhances our understanding of the heterogeneity of physical activity behaviour within and between days as well as provides new knowledge on the associations between different daily physical activity patterns and health-related physical fitness.

Our findings based on 24-hour accelerometer measurement and latent trajectory approach expand the previous literature, which has identified different patterns of physical activity based on selfreported data among adult populations (29-31). A recent Danish study also utilized accelerometer data and examined movement behavior profiles at work and leisure (8), but due to a different analytical approach and age distribution of the participants, detailed comparison of the results is difficult. However, similarly with ours, they also found different activity profiles characterized by variation in activity level at work and leisure. We identified 6 different trajectory groups on workdays when they found 4 distinct groups, which could be explained by the fact that Danish study population was much more homogeneous in terms of occupations and consisted of mainly blue-collar workers, whereas our study population included participants with various occupations.

An added value of our study was that we considered physical activity not only on workdays but also on days off. We found that there is much more diversity in physical activity patterns on workdays than on days off which can be partly explained by the wide variation of work-related tasks and requirements and different activity behaviors in the evening hours. We also observed that people who were less active in the evening hours on workdays showed also lower activity levels during days off contributing to lower overall physical activity. Although we conducted separate analyses for workdays and days off, considering total physical activity during the entire week is important when examining associations with health-related fitness. Therefore, the analyses regarding workday physical activity patterns were adjusted for activity level on days off, and vice versa.

To the best of our knowledge, this is the first study to examine associations between different activity patterns and various healthrelated physical fitness indicators. We found that people with low activity throughout the workday had more adiposity and poorer cardiorespiratory and lower- and upper-body muscular fitness in comparison to people with low or moderate activity during day, but higher activity in the evening, reflecting higher health enhancing leisure-time activity. We also found discrepancies between total activity volume and health-related physical fitness indicators. Although there was a clear difference in total daily activity volume between the "Low during the day and increase in the evening" (2308 VM CPM, 95\% CI 2168-2448), the "High during the day and decrease in the evening" (3083 VM CPM, 95\% CI 2960-3205), and the "Highest during the day and active in the evening" (3928 VM CPM, 95\% CI 3784-4073) groups, the health-related physical fitness indicators were relatively similar across the groups. However, the participants in the "High during the day and decrease in the evening" group tended to have higher adiposity than participants in the 2 other trajectory groups, which were more active in the evening, but due to low statistical power the differences were not statistically significant. These findings give support to the "physical activity paradox" suggesting that occupational physical activity, although at high volume but often monotonous with too little breaks, does not produce the same health benefits as leisure-time physical activity, which is characterized by voluntary and dynamic movements with enough recovery $(12,32)$. This is especially important for the aging workers for whom the physical working capacity may be reduced in respect to the occupational demands at work, and they are working at higher relative effort than the younger employees are. Moreover, transition from work to retirement may induce greater changes in daily physical activity for those who have had high level of occupational physical activity. Indeed, a recent study suggests that especially women who retired from manual occupations decreased their total physical activity after retirement (33).

On the other hand, the comparison between the 2 groups with highest occupational physical activity shows that the "High activity during day and decrease in the evening" group had a slightly higher adiposity, but similar cardiorespiratory and muscular fitness, than the "Highest activity during day and active in the evening" group. These findings must be interpreted in respect to the relatively high age of the study population and cross-sectional nature of this study. It is possible that physically demanding work may partly support maintenance of cardiorespiratory and muscular fitness among aging workers, but the differences in daily physical activity volume may explain lower adiposity in the "Highest activity during day and active in the evening" group. Moreover, there is also selection regarding the ability to continue working in physically demanding occupation until statutory retirement age and therefore the differences in health-related physical fitness across the different daily physical activity pattern groups could be larger in younger occupational cohorts and should be studied in future research.

The main strengths of the study include the data-driven trajectory modeling of hourly physical activity, which enabled us 
to identify various activity patterns throughout the day. In comparison to the previous studies relying on population-level average values, latent trajectory analysis allows examination of development and variation of physical activity over time. Second, physical activity measurements were based on wrist accelerometry allowing quantification of hour-by-hour patterns of physical activity over 24 hours across a number of days. This can overcome the limitations of self-reported measures of activity behaviour, which poorly capture light-intensity activities and physical activity at work and are subject to recall bias (34). Finally, our study population was very homogeneous in terms of their age and work ability, thus reducing bias due to age-related differences in physical activity and healthrelated physical fitness.

The study has also some limitations that warrant discussion. The indicator for physical activity volume was hourly and weekly VM CPM as used in the previous studies $(4-6,33)$. Currently, there are no validated count-based cutoff values for different activity intensities for wrist-worn accelerometers, and therefore it was not possible to compare activity levels in different physical trajectories to health recommendations. The current analyses aimed to examine variation in activity behavior within workdays and days off, but it would be interesting to examine even in more detail the variation within the working hours and leisure time on workdays to better capture the possible discrepancy in occupational and leisure-time physical activity. This kind of analysis requires larger sample size than was available for the current study. Future studies are needed to examine the patterns of different physical activity intensities within and between days, as well as reflecting them against the health recommendations.

To measure body composition, we used BIA, which has shown to overestimate lean body mass and underestimate fat mass compared to dual energy X-ray absorptiometry among people in their 60s (35). There was also nonparticipation in the push-up and bicycle ergometer tests, which was partly due to contraindications, but mainly reasons not related to the health status (ie, unwillingness to participate to a second study visit). Furthermore, the study population consisted of relatively healthy public sector employees in their 60s, and they were more active and had healthier weight compared to the FIREA participants who participated only in the study survey. This selective participation may have influenced on the identified physical activity patterns and their association with health-related physical fitness.

Moreover, the generalizability of the findings is limited to aging workers engaged in daytime work and mostly in femaledominated occupations. Finally, the study population as well as physical activity trajectory groups were relatively small leading to reduced statistical power to detect differences in health-related physical fitness indicators between the groups. Therefore, future studies with a larger sample size, broader age groups, and more balanced sex distribution are warranted to confirm the findings of the current study.

In conclusion, we observed a large variation in the daily physical activity patterns on workdays among aging workers. An activity pattern characterized by a low activity throughout the day was associated with poorest health-related physical fitness, whereas moderate activity during workday and increase of activity in the evenings were associated with more favorable body composition and better cardiorespiratory and muscular fitness. The results highlight the important role of leisure-time physical activity for better health-related physical fitness among aging workers.

\section{Supplementary Material}

Supplementary data are available at The Journals of Gerontology, Series A: Biological Sciences and Medical Sciences online.

\section{Funding}

This work was supported by the Academy of Finland (grants 286294, 294154, 319246, and 332030 to S.S.; 309526 to T.L.); Ministry of Education and Culture (to S.S.); Juho Vainio Foundation (to S.S.); and Hospital District of Southwest Finland (to S.S.).

\section{Conflict of Interest}

None declared.

\section{Acknowledgments}

The authors would like to thank the all participants who took part in the FIREA study and the FIREA study staff members for their contribution in the data collection.

\section{References}

1. Kyu HH, Bachman VF, Alexander LT, et al. Physical activity and risk of breast cancer, colon cancer, diabetes, ischemic heart disease, and ischemic stroke events: systematic review and dose-response meta-analysis for the Global Burden of Disease Study 2013. BMJ. 2016;354:i3857. doi:10.1136/ bmj.i3857

2. Robroek SJ, van den Berg TI, Plat JF, Burdorf A. The role of obesity and lifestyle behaviours in a productive workforce. Occup Environ Med. 2011;68:134-139. doi:10.1136/oem.2010.055962

3. Robroek SJ, Reeuwijk KG, Hillier FC, Bambra CL, van Rijn RM, Burdorf A. The contribution of overweight, obesity, and lack of physical activity to exit from paid employment: a meta-analysis. Scand J Work Environ Health. 2013;39:233-240. doi:10.5271/sjweh.3354

4. Pulakka A, Leskinen T, Koster A, Pentti J, Vahtera J, Stenholm S. Daily physical activity patterns among aging workers: the Finnish Retirement and Aging Study (FIREA). Occup Environ Med. 2019;76:33-39. doi:10.1136/oemed-2018-105266

5. Schrack JA, Zipunnikov V, Goldsmith J, et al. Assessing the "physical cliff": detailed quantification of age-related differences in daily patterns of physical activity. J Gerontol A Biol Sci Med Sci. 2014;69:973-979. doi:10.1093/gerona/glt199

6. Wennman H, Pietilä A, Rissanen H, et al. Gender, age and socioeconomic variation in 24-hour physical activity by wrist-worn accelerometers: the FinHealth 2017 Survey. Sci Rep. 2019;9:6534. doi:10.1038/s41598-019-43007-x.

7. Collins LM, Lanza ST. Latent Class and Latent Transition Analysis with Applications in the Social, Behavioral, and Health Sciences. Hoboken, NJ: John Wiley \& Sons; 2010.

8. Gupta N, Hallman DM, Dumuid D, et al. Movement behavior profiles and obesity: a latent profile analysis of 24-h time-use composition among Danish workers. Int J Obes (Lond). 2020;44:409-417. doi:10.1038/ s41366-019-0419-8

9. Metzger JS, Catellier DJ, Evenson KR, Treuth MS, Rosamond WD, SiegaRiz AM. Associations between patterns of objectively measured physical activity and risk factors for the metabolic syndrome. Am J Health Promot. 2010;24:161-169. doi:10.4278/ajhp.08051151

10. Li J, Siegrist J. Physical activity and risk of cardiovascular disease-a metaanalysis of prospective cohort studies. Int J Environ Res Public Health. 2012;9:391-407. doi:10.3390/ijerph9020391

11. Li J, Loerbroks A, Angerer P. Physical activity and risk of cardiovascular disease: what does the new epidemiological evidence show? Curr Opin Cardiol. 2013;28:575-583. doi:10.1097/HCO. ob013e328364289c 
12. Holtermann A, Hansen JV, Burr H, Søgaard K, Sjøgaard G. The health paradox of occupational and leisure-time physical activity. $\mathrm{Br}$ J Sports Med. 2012;46:291-295. doi:10.1136/bjsm.2010.079582

13. Coenen P, Huysmans MA, Holtermann A, et al. Do highly physically active workers die early? A systematic review with meta-analysis of data from 193696 participants. Br J Sports Med. 2018;52:1320-1326. doi:10.1136/ bjsports-2017-098540

14. Warburton DE, Nicol CW, Bredin SS. Health benefits of physical activity: the evidence. CMAJ. 2006;174:801-809. doi:10.1503/cmaj.051351

15. Leskinen T, Pulakka A, Heinonen OJ, et al. Changes in non-occupational sedentary behaviours across the retirement transition: the Finnish Retirement and Aging (FIREA) study. J Epidemiol Community Health. 2018;72:695-701. doi:10.1136/jech-2017-209958

16. Choi L, Ward SC, Schnelle JF, Buchowski MS. Assessment of wear/nonwear time classification algorithms for triaxial accelerometer. Med Sci Sports Exerc. 2012;44:2009-2016. doi:10.1249/MSS.0b013e318258cb36

17. Pulakka A, Shiroma EJ, Harris TB, Pentti J, Vahtera J, Stenholm S. Classification and processing of 24-hour wrist accelerometer data. J Measur Phys Behav. 2018;1:51-59. doi:10.1123/jmpb.2017-0008.

18. ActiGraph. What does the "Detect Sleep Periods" button do and how does it work? Accessed March 13, 2020. https://actigraphcorp.force.com/ support/s/article/What-does-the-Detect-Sleep-Periods-button-do-andhow-does-it-work.

19. Migueles JH, Cadenas-Sanchez C, Ekelund U, et al. Accelerometer data collection and processing criteria to assess physical activity and other outcomes: a systematic review and practical considerations. Sports Med. 2017;47:1821-1845. doi:10.1007/s40279-017-0716-0

20. Guralnik JM, Simonsick EM, Ferrucci L, et al. A short physical performance battery assessing lower extremity function: association with selfreported disability and prediction of mortality and nursing home admission. J Gerontol. 1994;49:M85-M94. doi:10.1093/geronj/49.2.m85

21. Suni JH, Oja P, Miilunpalo SI, Pasanen ME, Vuori IM, Bös K. Healthrelated fitness test battery for adults: associations with perceived health, mobility, and back function and symptoms. Arch Phys Med Rehabil. 1998;79:559-569. doi:10.1016/s0003-9993(98)90073-9

22. American College of Sports Medicine. ACSM's Guidelines for Exercise Testing and Prescription. 9th ed. Baltimore, MD: Wolters Kluwer, Lippincott Williams \& Wilkins; 2014.

23. Solovieva S, Pehkonen I, Kausto J, et al. Development and validation of a job exposure matrix for physical risk factors in low back pain. PLoS One. 2012;7:e48680. doi:10.1371/journal.pone.0048680

24. Stenholm S, Solovieva S, Viikari-Juntura E, Aalto V, Kivimäki M, Vahtera J. Change in body mass index during transition to statutory retirement: an occupational cohort study. Int J Behav Nutr Phys Act. 2017;14:85. doi:10.1186/s12966-017-0539-2

25. Kujala UM, Kaprio J, Sarna S, Koskenvuo M. Relationship of leisuretime physical activity and mortality: the Finnish twin cohort. JAMA. 1998;279:440-444. doi:10.1001/jama.279.6.440

26. Ainsworth BE, Haskell WL, Herrmann SD, et al. 2011 Compendium of physical activities: a second update of codes and MET values. Med Sci Sports Exerc. 2011;43:1575-1581. doi:10.1249/MSS.0b013e31821ece12

27. Leskinen T, Stenholm S, Heinonen OJ, et al. Change in physical activity and accumulation of cardiometabolic risk factors. Prev Med. 2018;112:31-37. doi:10.1016/j.ypmed.2018.03.020

28. Nagin DS, Odgers CL. Group-based trajectory modeling in clinical research. Annu Rev Clin Psychol. 2010;6:109-138. doi:10.1146/annurev. clinpsy.121208.131413

29. Charreire H, Casey R, Salze P, et al. Leisure-time physical activity and sedentary behavior clusters and their associations with overweight in middleaged French adults. Int J Obes (Lond). 2010;34:1293-1301. doi:10.1038/ ijo.2010.39

30. Salanave B, Vernay M, Szego E, et al. Physical activity patterns in the French 18-74-year-old population: French Nutrition and Health Survey (Etude Nationale Nutrition Sante, ENNS) 2006-2007. Public Health Nutr. 2012;15:2054-2059. doi:10.1017/s1368980012003278.

31. Aparicio-Ugarriza R, Pedrero-Chamizo R, Bibiloni MDM, et al. A novel physical activity and sedentary behavior classification and its relationship with physical fitness in Spanish older adults: the PHYSMED Study. J Phys Act Health. 2017;14:815-822. doi:10.1123/ jpah.2016-0263

32. Holtermann A, Krause N, van der Beek AJ, Straker L. The physical activity paradox: six reasons why occupational physical activity (OPA) does not confer the cardiovascular health benefits that leisure time physical activity does. Br J Sports Med. 2018;52:149-150. doi:10.1136/ bjsports-2017-097965

33. Pulakka A, Leskinen T, Suorsa K, et al. Physical activity across retirement transition by occupation and mode of commute. Med Sci Sports Exerc. 2020;52(9):1900-1907. doi:10.1249/mss.0000000000002326

34. Matthews CE, Hagströmer M, Pober DM, Bowles HR. Best practices for using physical activity monitors in population-based research. Med Sci Sports Exerc. 2012;44(1 suppl 1):S68-S76. doi:10.1249/ MSS.0b013e3182399e 5b

35. Sillanpää E, Cheng S, Häkkinen K, et al. Body composition in 18- to 88-year-old adults-comparison of multifrequency bioimpedance and dualenergy X-ray absorptiometry. Obesity (Silver Spring). 2014;22:101-109. doi:10.1002/oby.20583 